Session \# 2560

\title{
Engineering and the Millennium Development Goals
}

\author{
Dato' Ir Lee Yee-Cheong, President \\ World Federation of Engineering Organizations \\ Russel C. Jones, Chairman \\ WFEO Committee on Capacity Building
}

\begin{abstract}
This paper outlines elements of a global action program to apply science, technology and innovation (STI) to meeting the Millennium Development Goals (MDGs). For purposes of the report, STI is used to mean the generation, use and diffusion of all forms of useful knowledge as well as the evolution of associated institutional arrangements. The MDGs include: halving extreme poverty and hunger, achieving universal primary education and gender equity, reducing under-five mortality and maternal mortality by two-thirds and three-quarters respectively, reversing the spread of HIV/AIDS, halving the proportion of people without access to safe drinking water and ensuring environmental sustainability. They also include the goal of developing a global partnership for development, with targets for aid, trade and debt relief. As a long-term vision, the idea is to see achieving the MDGs as steps towards longer term targets for developing global learning mechanisms, which facilitate the building of internal capacity in developing countries such that the institutions for learning can in the long run act as an engine for growth in these countries.
\end{abstract}

\section{Introduction}

At the Millennium Summit in September 2000 world leaders passed the Millennium Declaration, which formally established the Millenium Development Goals. Since then the MDGs have become the international reference standard for measuring and tracking improvements in the human condition in developing countries. They have the advantage of (i) a political mandate agreed by the leaders of all UN member states, (ii) offering a comprehensive and multi-dimensional development framework, and (iii) setting clear quantifiable targets to be achieved in all countries by 2015 .

The full list of Millenium Development Goals follows:

Goal 1: Eradicate extreme poverty and hunger

Target 1: Halve, between 1990 and 2015, the proportion of people whose income is less than one dollar a day 
Target 2: $\quad$ Halve, between 1990 and 2015, the proportion of people who suffer from hunger

Goal 2: Achieve universal primary education

Target 3: Ensure that, by 2015, children everywhere, boys and girls alike, will be able to complete a full course of primary schooling

Goal 3: Promote gender equality and empower women

Target 4: Eliminate gender disparity in primary and secondary education, preferably by 2005, and to all levels of education no later than 2015

Goal 4: Reduce child mortality

Target 5: Reduce by two-thirds, between 1990 and 2015, the under-five mortality rate

Goal 5: Improve maternal health

Target 6: Reduce by three-quarters, between 1990 and 2015, the maternal mortality ratio

Goal 6: Combat HIV/AIDS, malaria and other diseases

Target 7: Have halted by 2015 and begun to reverse the spread of HIV/AIDS

Target 8: Have halted by 2015 and begun to reverse the incidence of malaria and other major diseases

Goal 7: Ensure environmental sustainability

Target 9: Integrate the principles of sustainable development into country policies and programmes and reverse the loss of environmental resources

Target 10: Halve, by 2015, the proportion of people without sustainable access to safe drinking water

Target 11: By 2020, to have achieved a significant improvement in the lives of at least 100 million slum dwellers

Goal 8: Develop a Global Partnership for Development

Target 12: Develop further an open, rule-based, predictable, nondiscriminatory trading and financial system

Target 13: $\quad$ Address the Special Needs of the Least Developed Countries

Target 14: Address the Special Needs of landlocked countries and small island developing States

Target 15: Deal comprehensively with the debt problems of developing countries through national and international measures in order to make debt sustainable in the long term

Target 16: $\quad$ In co-operation with developing countries, develop and implement strategies for decent and productive work for youth

Target 17: In co-operation with pharmaceutical companies, provide access to affordable, essential drugs in developing countries 
Target 18: $\quad$ In co-operation with the private sector, make available the benefits of new technologies, especially information and communications

\section{Task Force on Science, Technology and Innovation}

A Task Force on Science, Technology and Innovation has been established by the United Nations to address appropriate portions of the Millenium Development Goals. The aim of this Task Force is to outline elements of a global framework for promoting the application of science, technology and innovation (STI) to meeting the Millennium Development Goals (MDGs) adopted by the United Nations in the year 2000. The MDGs include targets on issues such as poverty, hunger, primary education, gender equality, child and maternal mortality, HIV/AIDS, malaria, TB and other major diseases as well as access to essential medicines. In addition, the goals stress sustainable development, safe water, upgrading slums, open, rule-based trading systems and technology transfer. Implementing goals related to these themes will require - among other measures - the generation, use and diffusion of new knowledge as well as adjustments in related institutions.

\section{Science, Technology and Innovation}

An analysis of Western economies and their history suggests that the prime explanations for the success of today's advanced industrialized countries lies in their history of innovation along different dimensions: institutions, technology, trade, organization, application of natural resources. Similar factors explain the economic transformation of recently industrialized countries in the developing world.

Thus, scientific and technological innovations come about through a process of institutional and organizational creation and modification; one does not precede the other neatly in time. Certainly, defining characteristics of the Western growth rates have been the institutionalization of private enterprise along with its financial and legal rubric, along with constantly attaining to lower cost of production and introducing new products on the market. There was also an exploitation of opportunities provided by trade and natural resources. This was a tribute to not just carrying through with new opportunities, but the abilities of the private sector and the State alike, for recognition of the new opportunities and ways in which to exploit them.

Technology affects human development through two major paths. Through innovation, it can directly affect human well being by increasing functionality of existing means to reduce poverty and increase human capabilities. This is most evident through technological innovations in human health, agriculture, and energy use and information and communication technologies. Secondly, it can also indirectly affect human wellbeing by enhancing productivity and thus economic growth and incomes. This productivity enhancement may be seen through increased output of workers, higher agricultural yields and heightened efficiency of services, while the higher incomes can 
again help to meet basic needs Thus STI helps directly, even without direct income increases, although it can help the latter as well. Importantly, it assists in overcoming the barriers of low-incomes and weak institutions.

STI capacity has been shown to be positively correlated to economic growth, although the extent to which the two are linked is not clear. Many fields of science have little connection to economic development, and many areas of economic growth do not rely on STI. Human development itself strengthens technology development. One cannot talk about competitiveness or increased capacity or productivity of industries, agriculture or the services sector without referring to the critical components that make up such systems: people and their knowledge. In fact, when human development is coupled to the knowledge people have and is encouraged to use to shape a better future, we can talk about self-sustainable human development: a process that aims at the betterment of the human condition, caring for the environment and building at present the conditions for a robust development in the future.

An important driving force of the adoption of technology, whether old or new, is higher income, but it is circular to argue that technology depends directly on higher incomes, when in fact technology may be a cause, not a result of increased uptake. An important additional point is that innovation itself may not be necessarily driven by higher incomes, but may fall out as a result of the adoption of certain technologies, which in turn may not have directly to do with higher incomes.

In summary, while it may help to be richer, the evidence is fuzzy about whether this is a result or a cause of technology use and diffusion. Indeed, innovation may thrive on increased resources being thrown at the problem, particularly finances, but it is no guarantee that innovation will occur. However, in developing countries, without funding, innovation through STI will hardly occur. In this sense, funding is necessary, but it is certainly not sufficient. The specific institutional mix of actors -individuals, firms, the State, other organizations, all serve to determine the milieu in which an innovation occurs within a specific technology.

The mutually reinforcing thrusts of human development and technology development serve to create a basis for a relationship between certain technologies and specific aspects of human development. For example, medical breakthroughs are linked to basic health, cheaper medicines and lower mortality rates; higher food production through better seeds, water sources and more efficient and less toxic fertilizers, is linked to better nutrition (particularly since most poor families around the world are farming families); ICTs serve to enhance information and participation through telephone, radio, $\mathrm{TV}$, fax and increasingly computers; and finally, manufacturing technologies drive industrial expansion, employment and worker incomes.

Yet, in addition to this seeming one-to-one relationship between certain technology advances and human development, each of the separate technology advances acts to reinforce the others. This is especially visible in medical technologies, where breakthroughs in genetics, coupled with computing advances, has opened up the world of 
drug discovery, development and manufacturing. Similarly, the advances in ICT technologies have themselves fuelled further gains to the agricultural, the manufacturing and the services sectors.

\section{Innovation}

The process of technological innovation involves interactions between a wide range of actors in society, forming a system of mutually-reinforcing learning activities. These interactions and the associated components constitute dynamic "innovation systems". Innovation "systems" can be understood by determining what varies in the institutional mixture, what is local and what is external. Thus within countries, the innovation "system" can have some common features, and also regional variations where technological dynamism is visible. Regional variations in innovation levels, technology adoption and diffusion and the institutional mix, are significant, even in the most developed countries.

In addition to comparing the innovative capacity of countries, attention is shifting to regions within countries. India is a case in point. While there are plenty of skilled scientists, engineers and doctors around the country, Bangalore is identified as the prime innovation hub, and Hyderabad an emerging one. This is a case where skilled professionals in a developing country gravitate to regions with adequate facilities and enabling environments. Thus, the national policy environment, while defining the early basis on which these city centers became competitive, has given way to an increased local innovative policy and entrepreneurial climate that have generated significant computer, telecommunications and more recently, pharmaceutical and biotechnology outputs.

While the it is unclear as to whether it is the local state governments or the private entrepreneurs who have been more relevant to this process, most people agree that the above two actors, large and small firms, universities and government laboratories have all had a part to play.

It has been advocated since long ago that government, private sector, universities and research institutions are important parts of a larger system of knowledge and interactions that allow diverse actors with varied strengths to come together around common broad goals for innovation. In many developing countries, the State and private sectors have varying capacities. The State often has the greatest capabilities, built through a history of import-substitution policies, when the public sector had a predominant role. On the other hand, private sector capacity for adapting tacit knowledge and mature technology and for absorbing new knowledge has varied by country, region, and by sector.

Universities, on the other hand, have largely languished across the developing world, with an unclear mandate, limited funds and lacking the flexibility to metamorphose to meet either basic needs (often dealt with by public research centers in "mission mode") or competitiveness (dealt with by the private sector or government training institutes). 
Although they have not been in the vanguard of development in many developing countries, they share with those of more advanced countries the new wave of demands towards more social accountability and more direct service to economic growth. It must be stressed, though, that in vast regions of the developing world, namely Latin America, universities, and more specifically public universities, are responsible for more than $75 \%$ of all $\mathrm{R} \& \mathrm{D}$ activities.

However, they often lack both the resources and the demand from a sound productive sector eager to benefit from the knowledge they might create. They suffer, thus, from a "loneliness syndrome" from which they cannot escape alone. To reverse this syndrome is one of the real challenges for development, one that cannot be fulfilled by pushing universities to change while everything else remains the same. A better approach is to channel energies within the university environment to fulfil a combined research, teaching and application mandate, with different types of universities taking on different challenges and government and industries engaging in effective interaction with them.

This is not a path without dangers, however. One of them is that the pendulum (to mix metaphors) could swing too far in the direction of making universities simply outposts for government or private sector service functions, or engaged entirely in applied research. Incentives need to be calibrated so, as universities continue to produce knowledge, they also seek to transfer that knowledge for useful applications where appropriate. Any informed science, technology and innovation policy needs to account for the fact that universities need continue to have local relevance while still fulfilling broader mandates of education and knowledge acquisition and diffusion.

It is perhaps easier to identify what does not make for innovation, rather than what does. Importantly, even if local environments are important for technological innovations such as malaria vaccines, wireless internet distribution and access, or using Global Positioning System (GPS) technology for farming or fishing, they are all faced with the challenge of keeping up with increasingly stringent global regulatory environments.

In the pharmaceutical industry, for example, this may be reflected in food and regulatory rules and certification for manufacturing facilities and output quality that may be administered differently by market and by new trading rules and WTO guidelines. In the information technology and telecommunications industry, this may be pressure from network externalities and the need to tie in to critical mass usage of a certain system or standard. Thus, neither innovation alone, nor even cutting edge technology, determines the eventual market uptake of the technology or the ability to keep up with regulatory pressures.

Both the Western and East Asian successes are characteristic of the "right" mix of institutional, technological and organizational elements that have given rise to STI, product, process and institutional dynamism. The challenge for underdeveloped countries is to re-think this powerful approach to adapt it to their specific conditions while bearing in mind the factors that make it particularly well fitted for development purposes: it explicitly acknowledges the political as well as institutional and cultural aspects of 
innovation processes; it stresses the importance of interactions between actors and organizations; it takes into account multiple actors with different roles, allowing to go beyond the dichotomy "state or market", making room for more "bottom-up" and associative networks; it highlights user-producer interactions, assigning an important role to usually neglected actors such as workers or consumers.

In China, where a blurred line exists between transitional forms of public and private enterprise, the challenge for government and the "private" sector alike has been to move from one set of institutions developed within the era of centralized economic planning, to another set, which is more market-friendly.

In Latin America, many governments have collapsed in a spiral of macroeconomic troubles fuelled by social deprivation, falling confidence levels in both economy and polity, and low investments in institutionalizing learning successes. Innovation in the sense of new products, processes or institutional creation, has been at best sporadic. Thus competitiveness has fallen, and with it, the ability of governments to provide for basic needs has also fallen.

Undoubtedly, capital flight from the region and the difficulty in attracting new investments has exacerbated existing rigidities. Yet, countries like Brazil and Mexico have made systematic attempts over the years to upgrade industry, access new technologies, and invest in education and training particularly for the working class.

However, the downside is that education and training, however, particularly when higher education is taken into consideration, continues to be extremely elitist, for far less than $20 \%$ of the young people in higher education age reach tertiary studies, against $50 \%$ average in OECD countries. Regional attempts at science, technology and broad-based innovation exist; but they need to be revitalized and given a broader mandate and platform for change.

\section{Role of industry}

While learning occurs in a variety of institutions, enterprises are the most critical locus at which learning of economic significance takes place. In other words, technological capabilities of economic importance accumulate at the enterprise level. Even the most state-friendly explanations of economic development in the academic, empirical and policy literature acknowledge that while government acts as a facilitator of institutionalizing knowledge acquisition/learning, the locus of that learning rests in enterprises-public or private. The structure of industrial organization and the nature of the production process itself, provide returns to scale of varying amounts based on input factors of skilled labour, robust management practices, other factors of production. The returns to deliberate investments that build innovative capacity show varying returns based on resource-base, institutional environment, among others.

Enterprises, particularly those involved in manufacturing, show great promise as centers of upgrading technology and organizational practices for developing countries. In addition, those enterprises that develop capabilities in design, $R \& D$ and product 
development, also establish themselves along a global value chain that allows for more opportunities for increased profit margins through innovation and product differentiation. Yet, manufacturing remains a core skill important to long-term enterprise learning. Historically, "industry has long been the main source, user and diffuser of technical progress and associated skills and attitudes...In this world the manufacturing industry is not just an ingredient of development-it is the essential ingredient" (UNIDO, 2002-2003). Both the fact that manufacturing can experiment with endless permutations of inputs in the production process as well as the fact that it can benefit from the increasing returns to scale of many industrial technologies, gives manufacturing a special place in the long road of economic development.

Furthermore, it is also a driver of innovation because relative to formal $R \& D$ processes, manufacturing actually affords a much greater opportunity for experimentation in engineering and production and also innovation on the procurement, quality and other management aspects of the organization. Furthermore, enterprises with manufacturing capability have been historically critically important not only for creating the new products, but also for diffusing new processes, organizational practices and learning opportunities for the labour force. In turn, enterprises act as a locus for spreading innovation outwards into the agricultural and service sectors.

At the outset, the scope of interest for enterprise is to master imported technologies and to gradually improve upon them in ways that benefit local production. This in itself, although called "imitation", is not an entirely straightforward process of replication. It involves complex learning activities and interactions with other players in the economy, including the source of the original innovation.

Perhaps most important, from an institutional and learning standpoint, is the historical role played by manufacturing enterprises in spearheading institutional change, particularly financial and legal, to support production processes worldwide. The extent to which these national institutions conform or diverge from global practice or those from first-mover countries, also defines the extent of convergence of learning speeds and economic development across countries.

This is not to make the case that we need homogeneity of institutions - in fact, evidence shows the opposite. To the extent that these national institutions are compatible with or open to other extra-national institutional changes, such as regulatory changes or trading rules, the more likely it is that national governments and domestic enterprises can make decisions that adapt local conditions quickly to the external economic and geo-political climate. The modernizing environment that was created by governments and firms alike in East Asia, by exposure to severe competition in export-oriented markets and by disciplinary measures hoisted on corporations by the governments of these countries, accelerated the investments made and the type of learning that took place across manufacturing enterprises.

However, the extent to which enterprises, and particularly SME, can play their role in innovation and social well-being is largely dependent on the internal skills they have at 
their disposal. Those are not only important for internal R\&D, but even more important to make sound decision regarding imported technologies. One of the big challenges for developing countries is the scarce participation of researchers in enterprises: in Latin America, Argentina, Brazil, Chile, Mexico, Uruguay, have only 20 or $30 \%$ of their researchers working in firms, compared with $70 \%$ in the US. Programs for helping SME to hire young engineers and other S\&T professionals, like those implemented in many European countries, can be critical to redress this weakness.

\section{Technological learning}

Technological learning involves bringing together a wide variety of disciplines, research cultures and tradition. It is largely a product of convergence between different technological traditions and therefore demands significant investment in coordination and management. A major hurdle preventing the commitment of the science, engineering and technology community to sustainable development is the preoccupation with maintaining and strengthening their own disciplinary turf. Achieving the MDGs requires crossdisciplinary and holistic approach. Science, engineering and technology know-how is not created within a single office or laboratory. An active process of sharing insights, problems, issues, experimental approaches, and outcomes creates knowledge. This occurs among people who have common interests, but they are not necessarily people within the same field of science, engineering or technology.

In fact, increasingly, the most interesting findings are emerging from the nexus of two or more fields of science and technology. As STI institutions are created, nurtured, and encouraged in developing countries, it is important to tie their missions to specific problems and to enable a rich cross-sectoral exchange of knowledge to occur. Care should be taken not to create a "physics center" that is physically distant from the chemistry laboratory. The same is true for biology and materials sciences. The sciences and the technologies emerging from them grow by interaction. The social sciences are also an integral part of this process, creating a context in which to understand the source, modes of creation and dissemination and impact of STI.

Thus, adjusting to the convergence across many areas of science, engineering and technology means encouraging organization that enables the flows of information across and among them. This can be done using ICT, as well as by pointing out the success stories of universities and research institutions that have "de-institutionalized" their departments and encouraged cross-sectoral research. A specific way to adjust convergence across STI is to develop a particular style and method of technology assessment like the one performed by NOTA, the Netherlands Office of Technology Assessment, where social and economic goals in need of innovation are translated into R\&D programs.

The biggest obstacle to cross-sectoral learning is the exaggerated pattern of narrow specialization that nowadays characterizes the search and application of knowledge. Encouraging, in all the possible range of stimuli and rewards, the organization of the 
research efforts by problems and not by disciplines, both in developing and developed countries, is a good way of fostering cross-sectoral learning. The problem is that researchers usually do not know how their knowledge can be used for addressing developmental problems; it is thus the responsibility of policy makers to devise strategies to help them find out how best they can contribute to development. One way to do this is to use a range of skills at their disposal and all combinations of inter-connected learning institutions to achieve the practical solutions of problems that can benefit the larger population.

\section{Conclusion}

This Task Force addresses MDG No.8 "Building Global Alliances for Development" and Target 18 "In cooperation with the private sector, make available the benefits of new technologies, especially information and communications". Its remit has been broadened to how science and technology can be enhanced and put to use to help all countries achieve the MDGs. The mission of the Task Force is guided by the understanding that most MDGs cannot be achieved without a strong contribution from a framework of action that seeks to place science and technology at the center of the development process.

Science and technology offers tools for solving acute problems, as well as for encouraging growth. It can also include earthquake detection, weather tracking, and disaster mediation. This use of science or technology can and should include a collection of experts from anywhere in the world. The aid they provide can help meet the Millennium Development Goals over the short term. The extent to which any country can solve acute problems often involves collective action. We expect that other MDG task forces will identify the ways in which STI can address acute needs such as these.

However, if long-term goals will be achieved, and growth and problem solving is to become indigenous and sustainable, then STI capabilities need to become a localized resource for developing countries. This latter goal is our focus, and it is one that requires a particular approach to STI as a system of interconnecting capabilities, each of which need attention. Governance is one, but education, institutions, advice, collaboration, and many other factors are also needed.

\section{Acknowledgement}

This draft paper quotes from an interim report of the Task Force on Science, Technology and Innovation of the United Nations Millennium Project. Full reports from this Task Force and the overarching Millenium Project are available on the World Wide Web:

"Investing in Development: A Practical Plan to Achieve the Millennium Development Goals", Jeffrey D. Sachs, Director, UN Millennium Project, http://unmp.forumone.com/ , 2005

"Innovation: applying knowledge in development", Calestous Juma and Lee Yee-Cheong, Task Force on Science, Technology and Innovation, http://unmp.forumone.com/eng task_force/ScienceEbook.pdf, 2005 
Academician DATO' IR. LEE YEE CHEONG, is President 2003-2005, of the World Federation of Engineering Organisations. During his career he has served with the National Electricity Board Malaysia, Tenaga Ewbank Preece (M) Sdn Bhd (TEP), and CEO, KTA Tenaga Sdn Bhd. He is a Coordinator of Task Force No.10 "Science, Technology and Innovation" of the UN Millennium Project, 20O2-2005.

RUSSEL C. JONES is a private consultant, working through World Expertise LLC to offer services in engineering education in the international arena. Prior to that, he had a long career in education: faculty member at MIT, department chair in civil engineering at Ohio State University, dean of engineering at University of Massachusetts, academic vice president at Boston University, and President at University of Delaware. 